\title{
Взаимодействие суперабсорбента «Твердая вода» модифицированного ионами цинка и марганца с водой
}

\author{
(С2020 Зенищева А.В., Семенов В.Н., Кузнецов В.А., \\ Кущев П.О., Лукин А.Н.
}

ФГБОУ ВО «Воронежский государственный университет», Воронеж

Поступила в редакцию 25.03.2020 г.

DOI: $10.17308 /$ sorpchrom.2020.20/2784

Одной из обсуждаемых проблем в сельскохозяйственной отрасли являются природно-климатические погодные изменения, проявляющиеся в виде глобального потепления, которые приводят к расширению зон засушливых районов и изменению почв. Последствием этих процессов является возрастание риска развития земледелия в этих зонах. Традиционно применяемые методы орошения и внесения в почву минеральных удобрений и микроэлементов не всегда доступны и эффективны. Для экономической выгоды и интенсификации рассматривается возможность применения ранее синтезированного редкосшитого полимерного материала со свойствами суперабсорбента «Твердая вода» в качестве не только резервуаров для поддержания требуемого уровня влажности, но и внесения в почву необходимых микроэлементов.

В данной работе изучены гидратационные свойства образцов суперабсорбента «Твердая вода», модифицированного солями сернокислого цинка и сернокислого марганца (II). Целью исследований являлось уточнение и корректировка полученных ранее результатов по гидратации образцов сорбента «Твердая вода», а также установление влияния электролитов $\mathrm{ZnSO}_{4}$ и $\mathrm{MnSO}_{4}$ в качестве микроэлементов на поглощение воды суперабсорбентом. В результате эксперимента определена способность модифицированных образцов сорбента к влагопоглощению, а также предложен способ определения установления энергетических параметров водородных связей в системе суперабсорбент - вода. Для этого использована универсальная программа обработки спектров (УПОС) по данным ИК-спектроскопии. Предложен один из возможных вариантов образования гидроксокомплексов «вода - ион металла» в фазе модифицированного микроэлементами сорбента.

В ходе исследования показано, что наибольшая энергия водородных связей характерна для гидроксокомплексов с участием карбоксилатных или карбоксильных групп в матрице сорбента. Для увеличения количества воды, поглощаемой суперабсорбентом, необходимо использовать его в катионной или анионной форме. Впервые установлено образование монодентатных и бидентатных лигандов при взаимодействии суперабсорбента с ионами сульфата цинка в растворе. Выявлено, что более стойкие ассоциаты образуются ионами $\mathrm{Zn}^{2+}$ с COОН- и аминогруппами, по сравнению с ионами $\mathrm{Mn}^{2+}$. Данные ИК-спектроскопии подтверждают, что влагопоглощение суперабсорбентом с $\mathrm{ZnSO}_{4}$ составляет

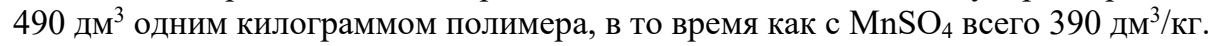

Ключевые слова: суперабсорбент, гидратационные свойства, влагопоглощение, сернокислый цинк, сернокислый марганец, ИК-спектры.

\section{Введение}

В работах [1-3] представлены результаты исследований по способам синтеза, влагопоглощающей способности и другим гидратационным свойствам полимерных суперабсорбентов «Твердая вода». Наилучшие результаты по влагопоглощению и набуханию были получены авторами [1-3] для O=C-NH- образцов «Твердая 
вода», синтезированных на основе биодеградирующих полисахаридов (крахмала, хи-

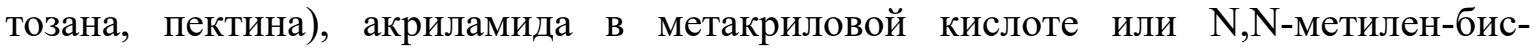
акриламида и окислительно-восстановительной инициирующей системы $\mathrm{H}_{2} \mathrm{O}_{2}+$ $\mathrm{Fe}_{2}\left(\mathrm{SO}_{4}\right)_{3}[1,3]$. В этом случае взаимодействовать с водой будут как неионогенные группы (гидроксильные группы полисахаридных звеньев, амидные группы), так и ионы (-COO$\left.-;-\mathrm{N}^{+} \mathrm{H}_{2}\right)$ (рис 1.) [3].
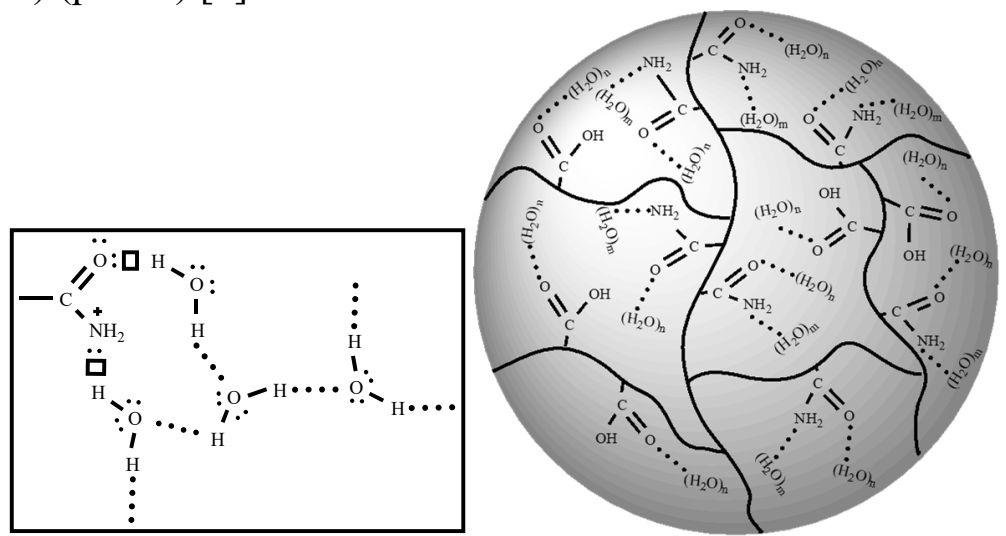

Рис. 1. Схема матрицы суперабсорбента «Твердая вода» [2,3].

Отнесение полос поглощения в ИК-спектрах исходного редкосшитого полимера «Твердая вода», пектина и исходного полимера, модифицированного пектином, приведено в таблице 1.

Таблица 1. Отнесение полос поглощения в ИК-спектрах редкосшитого полимерного материала со свойствами суперабсорбента и пектина [3].

\begin{tabular}{|c|c|c|c|}
\hline \multicolumn{3}{|c|}{$v, \mathrm{~cm}^{-1}$} & \multirow[b]{2}{*}{ Отнесение полос поглощения } \\
\hline $\begin{array}{l}\text { Исходный } \\
\text { полимер }\end{array}$ & Пектин & $\begin{array}{l}\text { Исходный } \\
\text { полимер + } \\
\text { пектин }\end{array}$ & \\
\hline 1 & 2 & 3 & 4 \\
\hline $\begin{array}{l}- \\
- \\
-\end{array}$ & $\begin{array}{c}- \\
3450 \\
3403\end{array}$ & $\begin{array}{c}3587 \\
- \\
-\end{array}$ & $\begin{array}{c}v_{\mathrm{s}} \mathrm{NH}_{2} \text { свободная в амидах; } v_{\mathrm{s}} \mathrm{OH}_{2} \cdot \bullet \cdot \mathrm{H}_{2} \mathrm{O} \\
\qquad v_{\mathrm{s}} \mathrm{OH}_{2} \bullet \bullet \cdot \mathrm{H}_{2} \mathrm{O}\end{array}$ \\
\hline $\begin{array}{c}3362 \\
- \\
3285 \\
3180\end{array}$ & $\begin{array}{l}3346 \\
3318 \\
3261 \\
3185\end{array}$ & $\begin{array}{c}- \\
3322 \\
3260 \\
3185\end{array}$ & $\begin{array}{c}v_{\mathrm{s}} \mathrm{NH}_{2} \text { связанная в первичных амидах; } \\
v_{\mathrm{s}} \mathrm{OH}_{2} \bullet \bullet \mathrm{O}=\mathrm{C} \text { ассоц. в первичных амидах (Амид I), } \\
v_{\mathrm{s}} \mathrm{OH}_{2} \bullet \bullet \mathrm{O}=\mathrm{C} \text { ассоц. с СООН-группами }\end{array}$ \\
\hline $\begin{array}{l}2928 \\
2852\end{array}$ & $\begin{array}{c}2941 \\
-\end{array}$ & $\begin{array}{l}2928 \\
2853\end{array}$ & $v_{\text {as }} \mathrm{CH}_{2} ; v_{\mathrm{s}} \mathrm{CH}_{2}$ \\
\hline $\begin{array}{c}2322 \\
-\end{array}$ & $\begin{array}{c}2340 \\
-\end{array}$ & $\begin{array}{c}- \\
2189\end{array}$ & -ОН в СООН (связаная) \\
\hline- & 1735 & 1735 & $v \mathrm{C}=\mathrm{O}$ в $\mathrm{COOH}$ \\
\hline $\begin{array}{c}1641 \\
1605 \\
-\end{array}$ & $\begin{array}{c}- \\
1617 \\
1518\end{array}$ & $\begin{array}{l}1648 \\
1610 \\
1464\end{array}$ & $v \mathrm{C}-\mathrm{N}$ и $\sigma_{\mathrm{s}} \mathrm{NH}$ в амидах (Амид II); $v_{\mathrm{as}} \mathrm{H}_{2} \mathrm{O}$ \\
\hline $\begin{array}{l}1406 \\
1380\end{array}$ & $\begin{array}{l}1419 \\
1371\end{array}$ & $\begin{array}{c}1406 \\
-\end{array}$ & $\begin{array}{c}\text { Амид III; } \\
\sigma-\mathrm{OH} \text { пиранозных колец; }\end{array}$ \\
\hline- & 1330 & 1309 & Веерные $\mathrm{CH}_{2} ;$ - $\mathrm{COOH}$ в димерах; \\
\hline $\begin{array}{c}1277 \\
-\end{array}$ & $\begin{array}{l}1238 \\
1146\end{array}$ & $\begin{array}{l}1240 \\
1152\end{array}$ & Маятниковые $\sigma_{\mathrm{s}} \mathrm{CH}$, Имеющие в конце - $\mathrm{COOH}$; \\
\hline
\end{tabular}




\begin{tabular}{|c|c|c|c|}
\hline 1 & 2 & 3 & 4 \\
\hline 1106 & 1102 & 1117 & \\
- & 1023 & - & $v_{\mathrm{s}} \mathrm{OH}_{2}$ в 6-членных циклах \\
962 & 962 & 979 & \\
\hline- & 930 & - & $\left(\mathrm{CH}_{2}\right)_{\mathrm{n}}-$ маятниковые \\
\hline- & 831 & 815 & \\
- & 687 & 750 & Амид III; $\sigma_{\mathrm{s}} \mathrm{CH} \mathrm{в} \mathrm{циклах}$ \\
- & 617 & - & \\
- & 536 & 550 & \\
\hline
\end{tabular}

Можно считать установленным, что в суперабсорбенте «Твердая вода» существенную роль в образовании короткоцепных фрагментов играют не только группы $\mathrm{COOH} ;-\mathrm{COO}^{-} ;-\mathrm{OH}$ - полисахаридных звеньев, но и амидные группировки. Подобный эффект для образования исходного полимера с пектином подтверждается наличием максимумов Амид I (3322, 3260, $\left.3185 \mathrm{~cm}^{-1}\right)$, Амид II $\left(1641,1610,1464 \mathrm{~cm}^{-1}\right)$, Амид III $\left(750,669,550 \mathrm{~cm}^{-1}\right)[3,4,7,9]$. Однако, влияние гидрофильных групп и амидных фрагментов на структуру воды будет в ряде случаев различно, что приводит как к разупорядочиванию Н-связей, так и к упрочнению их [5-12]. Подобные процессы приводят к появлению в ИК-спектрах слаборазрешенных, широких полос поглощения. Поэтому при исследованиях методом ИКС возникает необходимость в идентификации частично или полностью слившихся максимумов, что требует обработки полученных спектральных данных численными методами с применением компьютерных технологий. В нашем случае для обработки ИК-спектров была использована универсальная программа обработки спектров (УПОС) [13-17].

Разделение спектра $\mathrm{F}(\mathrm{x})$ на составляющие полосы проводили по методу дифференциальных моментов [17], который основан на совокупности нескольких операций $[14,15]$ :

1. Вычитание крыльев соседних максимумов;

2. Инверсия интенсивности;

3. Разложение в ряд Тейлора полученной функции $\mathrm{G}(\mathrm{x})$;

4. характеристиками индивидуальных пиков, (называемых дифференциальными моментами) являются коэффициенты разложения в ряд $\mathrm{A} n, \mathrm{~m}$ (где $\mathrm{n}$ - порядок производной; $\mathrm{m}$ - номер полосы в спектре). Дифференциальные моменты определяют по уравнению (1):

$$
A_{n, m}=\frac{A_{o, \bar{m}}}{n !} \cdot \frac{d^{n}}{d x^{n}} \cdot G_{m}(x),
$$

где $A_{o, \bar{m}}$ - нулевой дифференциальный момент; $A_{o, \bar{m}}=F(B)_{\bar{m}} \cdot B_{\bar{m}}$ - точка, в которой первый дифференциальный $A_{1, \bar{m}}=0$, т.е. максимум интенсивности $[15,17]$. Описание аналитического вида составляющих максимумов проводят путем использования обратного биквадратного трёхчлена, что позволяет не только разделить суммарные максимумы, но и сгладить шумы, проявляющиеся на экспериментальных кривых.

При первичной обработке проводится сглаживание [14,17]. Для серии спектров первоначально определяется количество полос в ИК-спектрах. Для этого каждый спектр обрабатывают отдельно в автоматическом режиме. Полученные данные второй производной анализируются вместе для всей изучаемой серии. Если минимум на графике второй производной, соответствующий некоторому пику [15], присутствует на всех графиках, то он считается достоверным. Присутствие минимума лишь на отдельных графиках характеризуется как шум [17]. Последующая обработка серии спектров включает получение параметров всех реально существующих пиков и их анализ [5-9]. (табл. 2). При неизменности параметров (положение, форма, ширина) во всей 
серии находят и фиксируют их средние значения. Если один из параметров менялся, допускают, что зависимость его от состава системы должна быть гладкой [17]. Поэтому аппроксимируют эту зависимость плавной кривой и в дальнейших расчетах берут с нее значения параметров, чтобы избежать их случайного разброса. Заключительная обработка результатов включала варьирование в серии только интенсивности полос. Правильность полученных результатов контролируется как по средним квадратным отклонениям между экспериментальным и модельным спектрами, так и непосредственно по разности между этими спектрами, которая выводится на график вместе с экспериментальным и модельным спектрами и полученными индивидуально пиками $[14,17]$. Разность между экспериментальными и модельными спектрами не превышает 7\%.

Таблица 2. Отнесение полос поглощения в ИК-спектрах исходного суперабсорбента «Твердая вода» до его контакта с водой [4,8,12-17].

\begin{tabular}{|c|c|c|c|}
\hline \multicolumn{2}{|c|}{$\mathrm{v}, \mathrm{cm}^{-1}$} & \multirow[b]{2}{*}{$\Delta v, \mathrm{~cm}^{-1}$} & \multirow[b]{2}{*}{ Колебания } \\
\hline $\begin{array}{l}\text { Исходный } \\
\text { сорбент }\end{array}$ & $\begin{array}{c}\text { По программе } \\
\text { УПОС }\end{array}$ & & \\
\hline- & 3506 & - & \multirow{2}{*}{$\begin{array}{c}\left.v \mathrm{H}_{2} \mathrm{O} \cdots \mathrm{H}_{2} \mathrm{O} \text { с } 3 \text { и } 2 \text { Н-связями (или } \mathrm{H}^{\cdots} \mathrm{OH}_{2}\right) \\
\qquad \mathrm{H}_{2} \mathrm{O} \cdots \mathrm{H}_{2} \mathrm{O} \text { с } 4 \text { Н-связямии }\end{array}$} \\
\hline 3408 & 3408 & 0 & \\
\hline 3396 & 3396 & 0 & $v \mathrm{H}_{2} \mathrm{O} \cdots \mathrm{HOOC}$ \\
\hline 3346 & 3371 & -25 & $v \mathrm{HOH}^{\cdots} \cdot{ }^{-} \mathrm{OOC}$ вблизи с $\mathrm{NH}$ \\
\hline 3290 & 3300 & -11 & $v_{\mathrm{s}} \mathrm{NH}$ \\
\hline 3206 & 3195 & 11 & Резонанс Ферми Амид I + Амид II c vNH \\
\hline 3089 & 3092 & 3 & Резонанс Ферми Амид IIx2 c vNH \\
\hline 2937 & 2937 & 0 & $v_{\text {as }} \mathrm{CH}_{2}$ \\
\hline 2840 & 2866 & 26 & $v_{\mathrm{S}} \mathrm{CH}_{2}$ \\
\hline 2648 & 2630 & 18 & $\sigma-\mathrm{COOH} \cdots \mathrm{OH}_{2}$ \\
\hline 2361 & 2350 & 11 & $v_{\mathrm{s}} \mathrm{H}$-связи в димерах СООН-групп \\
\hline 1666 & 1666 & 0 & $v_{\mathrm{s}}$ Амид $\mathrm{I}>\mathrm{C}=\mathrm{O} \cdots \mathrm{H}_{2} \mathrm{O}$ \\
\hline 1556 & 1556 & 0 & $v_{\mathrm{s}}$ Амид II C-N и $\sigma_{\mathrm{s}} \mathrm{N} ; v_{\mathrm{as}} \mathrm{H}_{2} \mathrm{O}$ \\
\hline 1449 & 1449 & 0 & $\sigma_{\text {II }} \mathrm{CH}_{2}$; вициальные амидные связи \\
\hline 1418 & 1401 & 17 & $\sigma_{\text {II }} \mathrm{CH}_{2} ;>\mathrm{C}=\mathrm{O}$ - вициальный \\
\hline 1316 & 1319 & -3 & $\gamma_{\mathrm{w}} \mathrm{CH}_{2} \mathrm{c}$ Амид III $\left(v_{\mathrm{s}} \mathrm{OCN}\right.$ c $\left.\sigma \mathrm{NH}\right)$ \\
\hline 1225 & 1229 & -4 & Амид III $+\gamma_{\mathrm{w}} \mathrm{CH}_{2}$ \\
\hline 1160 & 1163 & -3 & $v \mathrm{C}-\mathrm{N}$ и $\gamma_{\mathrm{t}} \mathrm{CH}_{2}$ \\
\hline 1124 & 1111 & 13 & $v \mathrm{C}-\mathrm{C}$ \\
\hline 1041 & 1042 & -1 & $\gamma_{\mathrm{t}} \mathrm{CH}_{2} ; \sigma \mathrm{CONH}$ (Амид IV) \\
\hline 835 & 837 & -2 & 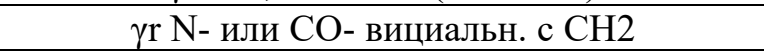 \\
\hline 792 & 792 & 0 & $\gamma_{\mathrm{r}} \mathrm{CH}_{2}$ \\
\hline 752 & 764 & -12 & $\gamma_{\mathrm{r}} \mathrm{CH}_{2} ;$ Амид $\mathrm{V}$ \\
\hline 624 & 617 & 7 & $v$ Амид VI $\left(\sigma_{0} \mathrm{C}=\mathrm{O}\right)$ \\
\hline 520 & 516 & 4 & v Амид VI \\
\hline
\end{tabular}

Для синтеза суперабсорбента, обогащенного $\mathrm{ZnSO}_{4}$ и $\mathrm{MnSO}_{4}$, применены два подхода. Первый из них состоял в насыщении микроэлементами предварительно высушенных и измельченных образцов базового полимерного материала из водных растворов соответствующих солей. После окончания сорбционного процесса образцы высушивают и используют в дальнейших физико-химических исследованиях. Соотношение сорбента по массе к раствору равнялось $1: 10$.

Второй подход заключался во введении водного раствора электролита в предполимеризационную систему как инициирующей части процесса радикальной поли- 
меризации или как инертного компонента в процессе синтеза полимера. В случае участия ионов переходных металлов как инициаторов полимеризации процесс осуществляют при температуре $30-40^{\circ} \mathrm{C}$; а в случае использования указанных ионов как инертных компонентов процесс ведут при $70^{\circ} \mathrm{C}$.

Целью исследований (с учетом вышесказанного) являлось уточнение и корректировка полученных ранее результатов по гидратации образцов сорбента «Твердая вода» [1-3], а также установление влияния электролитов $\mathrm{ZnSO}_{4}$ и $\mathrm{MnSO}_{4}$ в качестве микроэлементов на поглощение воды суперабсорбентом.

\section{Эксперимент}

При постановке и проведении эксперимента были учтены как особенности строения сорбента «Твердая вода» (рис. 1), так и предложены методические приемы, которые являются общепринятыми при определении физико-химических характеристик ионообменников $[8,11,12,17]$. Первым сакральным из таких подходов является проведение отмывки сорбента от примесей мономеров, не вступивших в реакцию полимеризации, а также от ионов-инициаторов этого процесса. Подобная операция именуется как кондиционирование. Необходимыми объектами исследования являются не только синтезированный сорбент, но и контактировавший с ним растворитель (вода).

Подготовку образцов для исследования проводили по методике [8]. ИК-спектроскопическое исследование порошкообразных образцов, закрепленных держателем на чувствительной поверхности призмы, проводили на ИК-спектрометре с Фурье-преобразователем Bruker Vertex 70 на одноходовой приставке НПВО «Platina». На pис. 2 и 3 приведены ИК-спектры исходного суперабсорбента и после его набухания в воде. Сплошной кривой обозначены экспериментальные результаты, штриховой линией расчеты УПОС. (А, \% - оптическая плотность).

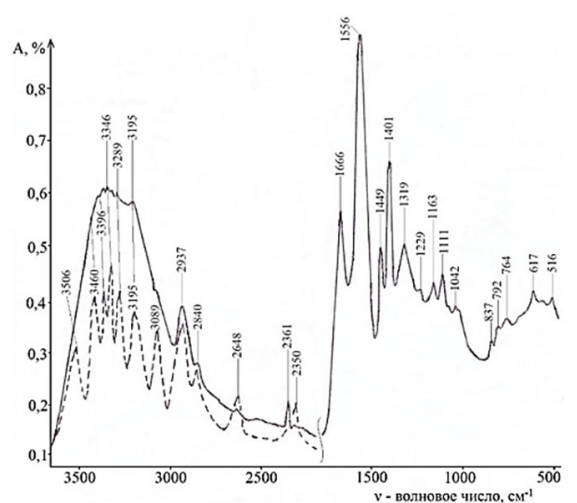

Рис. 2. ИК-спектры исходного

(сухого) суперабсорбента «Твердая вода» до контакта с водой.

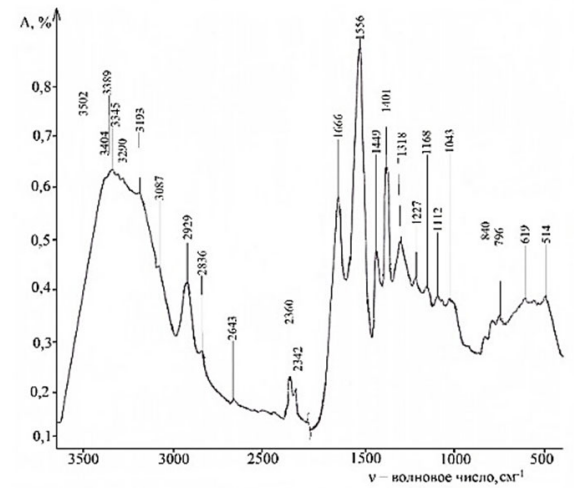

Рис. 3. ИК-спектры сорбента «Твердая вода» после набухания в дистиллированной воде.

Отнесение максимумов поглощения с учетом обработки спектров по универсальной программе обработки спектров представлено в таблице 2.

Следует отметить идентичность ИК-спектров образцов сорбента «Твердая вода» до контакта и последующего набухания в воде. Подобный артефакт отмечается впервые для суперабсорбента и он может быть вызван образованием воды в процессе полимеризации (уравнение 2):

$$
\mathrm{R}_{1}-\mathrm{COOH}+\mathrm{H}_{2} \mathrm{~N}-\mathrm{R}_{2} \rightarrow \mathrm{R}_{1}-\stackrel{\stackrel{\mathrm{O}}{\mathrm{C}}}{-}-\underbrace{\mathrm{N}}_{\mathrm{H}}-\mathrm{R}_{2}+\mathrm{H}_{2} \mathrm{O}
$$


где $\mathrm{R}_{1}$ и $\mathrm{R}_{2}$ - радикалы акриловой кислоты и $\mathrm{N}, \mathrm{N}$-метилен-бис-акриламида соответственно.

Последующее закрепление воды в сорбенте происходит за счет образования гидроксокомплексов с полярными группами (уравнение 3-5):

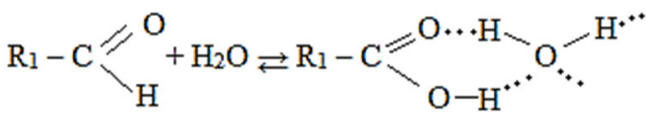

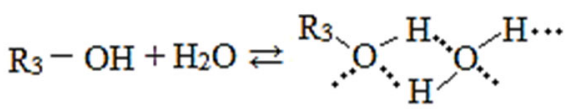

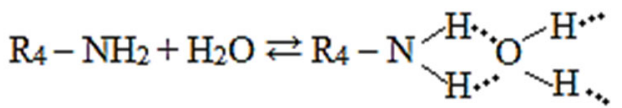

где $\mathrm{R}_{3}$ и $\mathrm{R}_{4}$ - радикалы полисахаридов и акриламида соответственно.

В связи с тем, что кондиционирование сорбента проводилось в статике, этот процесс продолжается до установления равновесия в системе суперабсорбент - вода. В результате при равновесии часть примесей должна диффундировать в растворитель $[11,12,17]$. Данные рисунка 4 и таблицы 3 свидетельствуют о том, что в дистиллят из сорбента переходит часть веществ - структурообразующих матрицу «Твердой воды». Прежде всего, это наличие полос поглощения в области $3500-3300 \mathrm{~cm}^{-1}$, пика $1642 \mathrm{~cm}^{-1}$ и пиков 1667 и $1556 \mathrm{~cm}^{-1}$, проявляющихся в исходном суперабсорбенте (рис. 2,3).

Кроме того, в ИК-спектрах растворителя после контакта с суперабсорбентом присутствует группа максимумов, характерных полиамидам: Амид I и Амид II (3200, $\left.3089 \mathrm{~cm}^{-1}\right)$; Амид III и Амид IV (1320, 1229, $\left.1042 \mathrm{~cm}^{-1}\right)$; Амид V и Амид VI (772, 617, $\left.516 \mathrm{~cm}^{-1}\right)[4,12]$. Таким образом процессы кондиционирования и равновесные процессы в системе сорбент - растворитель оказались совмещенными в одном цикле. Необходимо подчеркнуть, что сорбент в рассматриваемом случае проявляет свойства

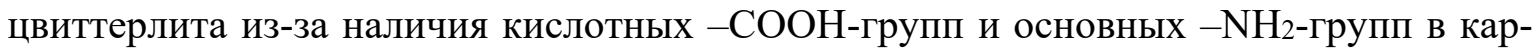
касе полимера $[8,11,12,17]$ (уравнение 6):

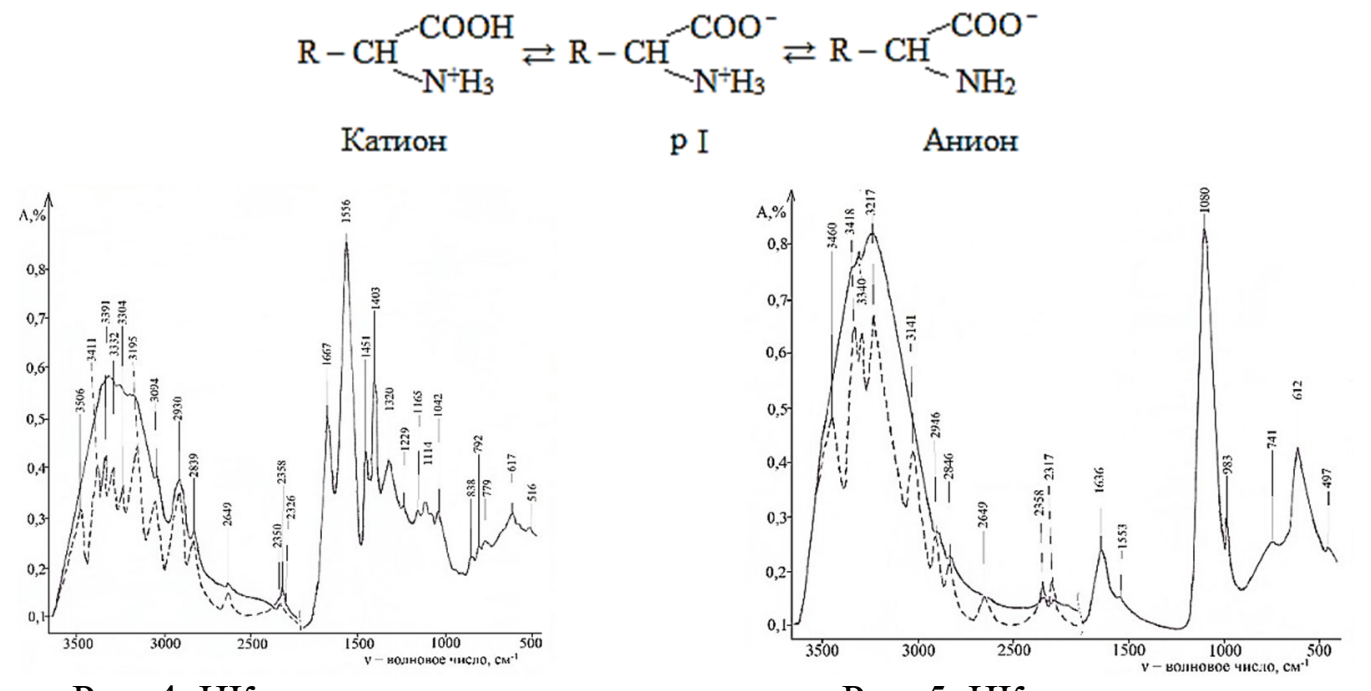

Рис. 4. ИК-спектры дистиллята воды после взаимодействия с исходным (сухим) суперабсорбентом «Твердая вода».
Рис. 5. ИК-спектры исходного (сухого) суперабсорбента с ионами сульфата цинка в растворе. 
Таблица 3. Отнесение полос поглощения в ИК-спектрах дистиллята воды после контакта с сухим исходным сорбентом «Твердая вода».

\begin{tabular}{|c|c|c|c|}
\hline \multicolumn{2}{|c|}{$v, \mathrm{~cm}^{-1}$} & \multirow[b]{2}{*}{$\Delta v, \mathrm{~cm}^{-1}$} & \multirow[b]{2}{*}{ Колебания } \\
\hline Эксперимент & $\begin{array}{l}\text { По программе } \\
\text { УПОС }\end{array}$ & & \\
\hline - & 3506 & - & $\begin{array}{c}v \mathrm{H}_{2} \mathrm{O} \cdots \mathrm{H}_{2} \mathrm{O} \text { с } 3 \text { и } 2 \text { Н-связями } \\
\left.\text { (или } \mathrm{NH}^{\cdots} \mathrm{OH}_{2}\right) \\
\end{array}$ \\
\hline 3411 & 3411 & 0 & $v \mathrm{H}_{2} \mathrm{O} \cdots \mathrm{H}_{2} \mathrm{O}$ с 4 Н-связями \\
\hline 3391 & 3391 & 0 & $v \mathrm{H}_{2} \mathrm{O} \cdots \mathrm{HOOC}$ \\
\hline 3332 & 3369 & -37 & $v \mathrm{HOH}^{\cdots} \cdot{ }^{-} \mathrm{OOC}$ вблизи с $\mathrm{NH}$ \\
\hline 3292 & 3304 & -12 & $v_{\mathrm{s}} \mathrm{NH}$ \\
\hline $\begin{array}{l}3195 \\
3094\end{array}$ & $\begin{array}{l}3195 \\
3094\end{array}$ & 0 & $\begin{array}{c}\text { Резонанс Ферми Амид I + Амид II c vNH } \\
\text { Резонанс Ферми Амид IIx2 c vNH }\end{array}$ \\
\hline 2930 & 2930 & 0 & $v_{\text {as }} \mathrm{CH}_{2}$ \\
\hline 2839 & 2839 & 0 & $v_{\mathrm{s}} \mathrm{CH}_{2}$ \\
\hline 2649 & 2649 & 0 & $\sigma-\mathrm{COOH} \cdots \mathrm{OH}_{2}$ \\
\hline 2358 & 2350 & 8 & $v_{\mathrm{s}} \mathrm{H}$-связи в димерах СООН-групп \\
\hline 1667 & 1667 & 0 & $v_{\mathrm{s}}$ Амид $\mathrm{I}>\mathrm{C}=\mathrm{O} \cdots \mathrm{H}_{2} \mathrm{O}$ \\
\hline 1556 & 1556 & 0 & $v_{\mathrm{s}}$ Амид II C-N и $\sigma_{\mathrm{s}} \mathrm{N} ; v_{\mathrm{as}} \mathrm{H}_{2} \mathrm{O}$ \\
\hline 1451 & 1451 & 0 & $\sigma_{\text {II }} \mathrm{CH}_{2} ;$ вициальные амидные связи \\
\hline 1403 & 1401 & -2 & $\sigma_{\mathrm{II}} \mathrm{CH}_{2} ;>\mathrm{C}=\mathrm{O}$ - вициальный \\
\hline 1320 & 1320 & 0 & $\gamma_{\mathrm{w}} \mathrm{CH}_{2} \mathrm{c}$ Амид III $\left(v_{\mathrm{s}} \mathrm{OCN}\right.$ c $\left.\sigma \mathrm{NH}\right)$ \\
\hline 1229 & 1229 & 0 & Амид III $+\gamma_{\mathrm{w}} \mathrm{CH}_{2}$ \\
\hline 1165 & 1165 & 0 & $v \mathrm{C}-\mathrm{N}$ и $\gamma_{\mathrm{t}} \mathrm{CH}_{2}$ \\
\hline 1114 & 1114 & 0 & $v \mathrm{C}-\mathrm{C}$ \\
\hline 1042 & 1042 & 0 & $\gamma_{\mathrm{t}} \mathrm{CH}_{2} ; \sigma \mathrm{CONH}$ (Амид IV) \\
\hline 838 & 838 & 0 & $\gamma_{\mathrm{r}} \mathrm{N}-$ или CO- вициальн. с CH2 \\
\hline 792 & 792 & 0 & $\gamma_{\mathrm{r}} \mathrm{CH}_{2}$ \\
\hline 779 & 779 & 0 & $\gamma_{\mathrm{r}} \mathrm{CH}_{2} ;$ Амид V \\
\hline 617 & 617 & 0 & $v$ Амид VI $\left(\sigma_{0} \mathrm{C}=\mathrm{O}\right)$ \\
\hline 516 & 516 & 0 & $v$ Амид VI \\
\hline
\end{tabular}

Полагая, что наличие в фазе суперабсорбента карбоксильных, карбоксилатных, спиртовых и аминогрупп сопровождается образованием различных по прочности гидратных структур, можно охарактеризовать их проявление энергетическими величинами (энтальпия, силовые постоянные Н- и ОН-связей, энергия, удлинение ковалентной связи, длины водородных мостиков) по формулам, приведенным в таблице 4. При этом расчеты энергетических параметров водородных связей учитывали, как экспериментальное, так и определенное по программе УПОС смещение полос поглощения в ИК-спектрах.

Таблица 4. Формулы для расчета параметров водородного мостика по величинам смещения в ИК-спектрах образцов сперабсорбента «Твердая вода» [5-12,16,17].

\begin{tabular}{|c|c|c|c|}
\hline Параметр & Символ & Ед.измерения & Формула для расчета \\
\hline 1 & 2 & 3 & 4 \\
\hline Энергия Н-связи & $\mathrm{E}_{\mathrm{H}}$ & кДж/моль & $-\Delta \mathrm{v} / \mathrm{v}^{\circ} \mathrm{OH}=\mathrm{E}_{\mathrm{H}} \cdot 1.6 \cdot 10^{-2}$ \\
\hline Энтальпия & $\Delta \mathrm{H}$ & кДж/моль & $\begin{array}{c}-\Delta \mathrm{H}=2.9 \Delta \mathrm{A}^{1 / 2} \\
\Delta v=\left[\Delta \mathrm{A}^{1 / 2}\right]^{2} \cdot 80\end{array}$ \\
\hline Силовая постоянная Н-связи & $\mathrm{K}_{\mathrm{H}}$ & $\mathrm{cm}^{-2}$ & $\mathrm{~K}_{\mathrm{H}}=(5.5 \pm 1.2) \cdot 10^{4} \cdot \mathrm{E}_{\mathrm{H}}$ \\
\hline \multirow{2}{*}{ Силовая постоянная ОН-связи } & $\mathrm{K}_{\mathrm{OH}}$ & кДж/моль & $\begin{array}{c}-\mathrm{K}_{\mathrm{OH}}=8.63 \cdot(5.5 \pm 1.2) \cdot 10^{4} \cdot \mathrm{E}_{\mathrm{H}} \\
-12.879 \cdot 10^{6}\end{array}$ \\
\hline
\end{tabular}




\begin{tabular}{|c|c|c|c|}
\hline 1 & 2 & 3 & 4 \\
\hline & $\mathrm{R}_{\mathrm{OH} \cdots \mathrm{O}}$ & $\AA$ & $\Delta v=4.4 \cdot 10^{3}\left(2.84-\mathrm{R}_{\mathrm{O} \cdots \mathrm{O}}\right)$ \\
& $\mathrm{R}_{\mathrm{OH} \cdots \mathrm{N}}$ & $\AA$ & $\Delta v=6.92 \cdot 10^{2}\left(3.04-\mathrm{R}_{\mathrm{O}} \cdots \mathrm{N}\right)$ \\
Длина водородного мостика & $\mathrm{R}_{\mathrm{NH} \cdots \mathrm{O}}$ & $\AA$ & $\Delta v=5.48 \cdot 10^{2}\left(3.21-\mathrm{R}_{\mathrm{N} \cdots \mathrm{O})}\right)$ \\
& $\mathrm{R}_{\mathrm{NH} \cdots \mathrm{N}}$ & $\AA$ & $\Delta v=1.05 \cdot 10^{3}\left(3.38-\mathrm{R}_{\mathrm{N}} \cdots \mathrm{N}\right)$ \\
\hline Удлинение ковалентной связи & $\Delta \mathrm{r}_{\mathrm{OH}}$ & $\AA$ & $\Delta \mathrm{r}_{\mathrm{OH}}=5.3 \cdot 10^{-5} \cdot \Delta v$ \\
\hline
\end{tabular}

$v_{0}$ для $\mathrm{R}_{\mathrm{OH} \cdots \mathrm{O}}=3700 \mathrm{~cm}^{-1} ; v_{0}$ для $\mathrm{R}_{\mathrm{OH} \cdots \mathrm{N}}=3400 \mathrm{~cm}^{-1} ; v_{0}$ для $\mathrm{R}_{\mathrm{NH} \cdots \mathrm{O}}=3550 \mathrm{~cm}^{-1} ; v_{0}$ для $\mathrm{R}_{\mathrm{NH} \cdots \mathrm{N}}=3300 \mathrm{~cm}^{-1}$.

Данные таблицы 5 свидетельствуют о больших сдвигах частоты в коротковолновую область при образовании Н-связей (до 2600-2300 см-1), что соответствует большой прочности гидратных комплексов в фазе исходного суперабсорбента. Анализ полученных термодинамических величин (рис. 2-4, табл. 5) показывает, что смещение $\Delta v \mathrm{OH}$ зависит от природы донора и акцептора протона, расстояния $\mathrm{R}$ между ними, длины ковалентных связей $-\mathrm{OH}$ и $-\mathrm{NH}$, растяжения-сжатия Н-связи. Наибольшая энергия водородных связей характерна для гидроксокомплексов с участием карбоксилатных или карбоксильных групп в матрице сорбента. Известно, что присутствие в любой системе биполярных ионов приводит к наименьшей (по сравнению с катионной и анионной формами) гидратации. Поэтому для увеличения количества воды, поглощаемой суперабсорбентом, необходимо использовать его в катионной или анионной форме. Для этого были использованы микродобавки солей $\mathrm{ZnSO}_{4}$ и $\mathrm{MnSO}_{4}$ в контактирующий с сорбентом растворитель.

Данные ИК-спектров (рис. 5, 6) свидетельствует о значительном увеличении количества поглощённой воды и сухим сорбентом $\left(\mathrm{c} \mathrm{ZnSO}_{4}\right)$ и влажным сорбентом (с $\mathrm{ZnSO}_{4}$ ). Доминирующими в ИКС образцов сухого полимера (модифицированного $\mathrm{ZnSO}_{4}$ ) после их увлажнения являются полосы при $3217 \mathrm{~cm}^{-1}$ (резонанс Ферми Амид I + Амид II c v NH) и 1080 cм$^{-1}\left(v \mathrm{C}-\mathrm{N}^{+}\right.$, бидентатный лиганд $\left.\mathrm{SO}_{4}{ }^{2-} \mathrm{C}_{2 v}\right)[4,18]$.

Таблица 5. Энергетические параметры водородных связей в системе суперабсорбент «Твердая вода» - $\mathrm{H}_{2} \mathrm{O}$ по данным ИК-спектроскопии.

\begin{tabular}{|c|c|c|c|c|c|c|c|c|}
\hline$\frac{v \text { исх }}{v \text { УПОС }}$ & $\frac{v \text { наб }}{v \text { УПОС }}$ & $\frac{\Delta v^{\circ} \text { исх }}{\Delta v \text { УПОС }}$ & $\frac{E \text { эксп }}{E \text { УПОС }}$ & $\frac{\Delta \mathrm{H} \mathrm{эксп}}{\Delta \mathrm{H} \mathrm{УПОС}}$ & $\frac{K_{H} \text { ЭКсп }}{K_{H} \text { УПОС }}$ & $\frac{K_{\mathrm{OH}} \text { ЭКсП }}{K_{\mathrm{OH}} \text { УПОС }}$ & $\frac{\text { RO } \cdots \text { О эксп }}{\text { RO } \cdots \text { О УПОС }}$ & $\begin{array}{l}\Delta \mathrm{r}_{\mathrm{OH}}, \\
\AA \cdot 10^{2}\end{array}$ \\
\hline & $\mathrm{CM}^{-1}$ & & кДж/ & кДж/ & $\mathrm{cm}^{-2} \cdot 10^{5}$ & $\mathrm{~cm}^{-2} \cdot 10^{5}$ & $\frac{\text { RNH } \cdots 0 \text { эксп }}{\frac{\text { RNH } \cdots \text { О УПОС }}{}}$ & \\
\hline & & & & & & & $\frac{\mathrm{ROH} \cdots \mathrm{N} \text { эксп }}{\mathrm{ROH} \cdots \mathrm{N} \text { УПОС }}$ & \\
\hline & & & & & & & $\begin{array}{c}\text { RNH } \cdots \text { N эксп } \\
\text { RNH } \cdots \text { N УПОС } \\
\AA\end{array}$ & \\
\hline 1 & 2 & 3 & 4 & 5 & 6 & 7 & 8 & 9 \\
\hline V ИСХ & $v$ наб & $\Delta v^{\circ}$ исх & 15.0 & 19.1 & 1.890 & 11.024 & 3.12 & 1.01 \\
\hline 3506 & $\overline{3506}$ & 194 & & & & & & \\
\hline 3420 & 3420 & 280 & 19.9 & 22.7 & 2.633 & 11.599 & 2.93 & 1.48 \\
\hline$\overline{3408}$ & 3411 & 292 & 20.6 & $\overline{23.0}$ & $\overline{2.906}$ & $\overline{11,306}$ & $\overline{2.93}$ & 1.40 \\
\hline 3396 & 3396 & 304 & 21.8 & 23.7 & 2.869 & 10.400 & 2.90 & 1.62 \\
\hline$\overline{3390}$ & $\overline{3391}$ & $\overline{310}$ & $\overline{21.6}$ & $\overline{23.9}$ & $\overline{2.873}$ & $\overline{10.463}$ & $\overline{2.91}$ & $\overline{1.64}$ \\
\hline 3346 & 3346 & 354 & 25.2 & 25.6 & 3.303 & 10.017 & 2.89 & 1.92 \\
\hline$\overline{3371}$ & $\overline{3292}$ & $\overline{320}$ & $\overline{22.7}$ & $\overline{24.4}$ & $\overline{2.980}$ & $\overline{10.318}$ & $\overline{2.91}$ & 1.70 \\
\hline
\end{tabular}




\begin{tabular}{|c|c|c|c|c|c|c|c|c|}
\hline 1 & 2 & 3 & 4 & 5 & 6 & 7 & 8 & 9 \\
\hline$\frac{3289}{3300}$ & $\frac{3292}{3300}$ & $\frac{264}{250}$ & $\frac{19.0}{18.8}$ & $\frac{21,9}{22,3}$ & $\frac{2.490}{2.341}$ & $\frac{10.850}{10.612}$ & $\frac{2.73}{2.73}$ & $\frac{1.42}{1.22}$ \\
\hline$\frac{3195}{3206}$ & $\frac{3195}{3200}$ & $\frac{211}{208}$ & $\frac{25.2}{24.9}$ & $\frac{24.6}{25.3}$ & $\frac{3.088}{3.131}$ & $\frac{9.955}{10.203}$ & $\frac{2.72}{2.72}$ & $\frac{1.92}{1.80}$ \\
\hline$\frac{3089}{3092}$ & $\frac{v \text { наб }}{3092}$ & $\frac{211}{208}$ & $\frac{15.1}{14.3}$ & $\frac{18.9}{18.0}$ & $\frac{2.006}{1.981}$ & $\frac{11.126}{12.305}$ & $\frac{2.71}{2.71}$ & $\frac{1.21}{1.69}$ \\
\hline$\frac{2648}{2630}$ & $\frac{v \text { наб }}{2649}$ & $\frac{1052}{1080}$ & $\frac{73.9}{77.1}$ & $\frac{43.5}{44.9}$ & $\frac{9.876}{9.992}$ & $\frac{4.373}{4.170}$ & $\frac{2.68}{2.73}$ & $\frac{5.60}{5.72}$ \\
\hline$\frac{2361}{2350}$ & $\frac{v \text { наб }}{2350}$ & $\frac{1339}{1350}$ & $\frac{92.6}{93.4}$ & $\frac{51.7}{53.0}$ & $\frac{12.590}{13.009}$ & $\frac{2.351}{2.284}$ & $\frac{2.59}{2.61}$ & $\frac{6.08}{5.94}$ \\
\hline
\end{tabular}

Особо необходимо отметить наличие максимумов при 1095, 983 и 612 см-1 (монодентатные лиганды $\mathrm{SO}_{4}{ }^{2-} v_{1} \mathrm{SO}$ в комплексах с $\mathrm{Zn}^{2+}$ ) (схема 7).

$$
\left(983 \mathrm{~cm}^{-1}\right) \mathrm{Zn}-\mathrm{O}-\stackrel{\mathrm{O}}{*} \rightleftarrows \mathrm{Zn} \sim \mathrm{O} \rightleftharpoons \mathrm{O} \rightleftharpoons \mathrm{O} \rightleftharpoons\left(1095 \mathrm{~cm}^{-1}\right)
$$

Подобный эффект установлен впервые и он не является характерным для образцов сорбента, контактировавшего в набухшем состоянии с раствором $\mathrm{ZnSO}_{4}$ (рис. 6). При этом для вышеуказанных образцов доминирующим являются максимумы 3206 $\mathrm{cm}^{-1}$ (резонанс Ферми Амид II c $v$ NH) и $1548 \mathrm{~cm}^{-1}\left(v_{\mathrm{s}}\right.$ Амид II C-N и $\left.\sigma_{\mathrm{s}} \cdot \mathrm{N}\right)$ [4]. Эти особенности свидетельствуют о наличии комплексов $\mathrm{Zn}{ }^{2+}$ с лигандами различного состава [9,18]. Набухаемость образцов суперабсорбента, обогащенных $\mathrm{ZnSO}_{4}$, достигает 490 дм $^{3}$ на 1 кг полимера.

Обработка ИК-спектров по программе УПОС позволила установить образование в фазе суперабсорбента комплексов с $\mathrm{Zn}^{2+}$ различного состава и амидных группировок Амид I, Амид II, Амид III, Амид IV, Амид V и Амид VI (рис. 6).

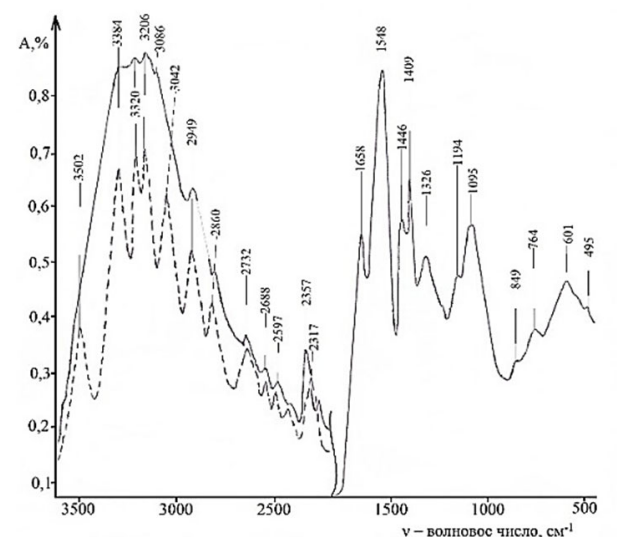

Рис. 6. ИК-спектры сорбента «Твердая вода» после набухания в растворе сульфата цинка.

В табл. 6 приведены данные колебаний в ИК-спектрах исходного (сухого) и набухшего сорбента «Твердая вода», модифицированного раствором сульфата цинка. Анализ данных табл. 6 позволил предложить один из возможных вариантов образования аквакомплексов в фазе модифицированного сорбента.

В растворе $\mathrm{ZnSO}_{4}$ содержатся как монодентатные лиганды, так и бидентатные 
лиганды. Ионы $\mathrm{Zn}^{2+}$ относятся к Б-катионам, и соответственно Льюису их можно рассматривать как «мягкие» кислоты (по Пирсону), т.е. как легко деформируемые шарики (легко поляризуемые). Комплексы Б-катионов более ковалентные, чем ионные. Ковалентность комплексов Б-катионов возрастает с увеличением их размеров. Некоторые авторы [19] считают, что ионы $\mathrm{Zn}^{2+}$ могут при образовании хелатных структур занимать промежуточное положение. В ряду Ирвинга-Вильямса, устанавливающий следующий ряд устойчивости комплексов (схема 8),

$$
\mathrm{Mn}^{2+}<\mathrm{Fe}^{2+}<\mathrm{Co}^{2+}<\mathrm{Ni}^{2+}<\mathrm{Cu}^{2+}<\mathrm{Zn}^{2+}
$$

Таблица 6. Отнесение полос поглощения в ИК-спектрах исходного (числитель) и набухшего (знаменатель) суперабсорбента «Твердая вода» в растворе сульфата цинка.

\begin{tabular}{|c|c|c|c|}
\hline \multicolumn{2}{|c|}{$v, \mathrm{~cm}^{-1}$} & \multirow[b]{2}{*}{$\Delta v, \mathrm{~cm}^{-1}$} & \multirow[b]{2}{*}{ Колебания } \\
\hline Эксперимент & $\begin{array}{l}\text { По программе } \\
\text { УПОС }\end{array}$ & & \\
\hline $0 / 0$ & $3460 / 3502$ & -58 & $\begin{array}{c}v \mathrm{H}_{2} \mathrm{O} \cdots \mathrm{H}_{2} \mathrm{O} \text { с } 3 \text { и } 2 \mathrm{H} \text {-связями } \\
\left.\text { (или } \mathrm{NH}^{\cdots} \mathrm{OH}_{2}\right)\end{array}$ \\
\hline $0 / 0$ & $3418 / 3384$ & -34 & $v \mathrm{H}_{2} \mathrm{O} \cdots \mathrm{H}_{2} \mathrm{O}$ с 4 Н-связями (или $\mathrm{NH}_{2} \rightarrow \mathrm{Zn}^{2+}$ ) \\
\hline $3340 / 3320$ & $3340 / 3320$ & 20 & $\begin{array}{c}v \mathrm{H}_{2} \mathrm{O} \cdots \mathrm{HOOC} \mathrm{вблизи} \mathrm{с} \mathrm{NH}_{2} \text { (или } v_{\mathrm{s}} \mathrm{COO}^{-} \cdots \\
\mathrm{H}_{2} \mathrm{O} \text { с Zn }{ }^{2+} \text { ) }\end{array}$ \\
\hline $3217 / 3206$ & $3217 / 3206$ & 11 & 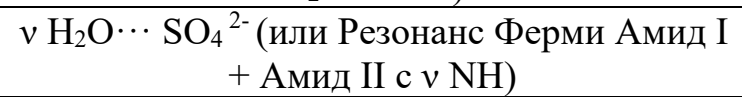 \\
\hline $0 / 0$ & $3141 / 3086$ & 0 & $\begin{array}{c}v \mathrm{NH} \cdots \text { - ООС ( или Резонанс Ферми Амид } \\
\text { IIx2 c NH) }\end{array}$ \\
\hline $2946 / 2949$ & $2946 / 2949$ & $-3 /-3$ & $v_{\mathrm{as}} \mathrm{CH}_{2}$ \\
\hline $2846 / 2860$ & $2846 / 2860$ & $0 / 0$ & $v_{\mathrm{s}} \mathrm{CH}_{2}$ \\
\hline $2649 / 2649$ & $2688 / 2688$ & $-39 /-39$ & $\begin{array}{c}\sigma \mathrm{COOH} \cdots \mathrm{OH}_{2} \text { или } v_{\mathrm{s}} \mathrm{H}-\text { связи в димерах } \\
\text { СООН-групп }\end{array}$ \\
\hline $0 / 0$ & $2597 / 2597$ & $0 / 0$ & $\begin{array}{c}\text { комплекс } \mathrm{Zn}^{2+} \text { с концевыми группами ами- } \\
\text { нокислот }\end{array}$ \\
\hline $2358 / 2357$ & $2358 / 2357$ & $0 / 0$ & $v_{\mathrm{s}} \mathrm{H}$-связи в димерах СООН-групп \\
\hline $1636 / 1658$ & $1639 / 1658$ & $-3 / 0$ & $v_{\mathrm{s}}$ Амид I (или $\mathrm{C}=\mathrm{O} \cdots \mathrm{H}_{2} \mathrm{O}$ с Zn ${ }^{2+}$ ) \\
\hline $1563 / 1548$ & $1563 / 1548$ & $0 / 0$ & $v_{\mathrm{s}}$ Амид II $\left(\mathrm{C}-\mathrm{N}\right.$ и $\left.\sigma_{\mathrm{s}} \mathrm{N}\right)$ или $v \mathrm{NH} \cdots \mathrm{H}_{2} \mathrm{O}$ \\
\hline $0 / 1446$ & $0 / 1446$ & $0 / 0$ & $\begin{array}{c}\sigma_{\text {II }} \text { вициальный } \mathrm{CH}_{2} ; \text { вициальные амидные } \\
\text { связи }\end{array}$ \\
\hline $0 / 1409$ & $0 / 1409$ & $0 / 0$ & $\sigma_{\mathrm{II}} \mathrm{CH}_{2} ;>\mathrm{C}=\mathrm{O}-$ вициальный \\
\hline $0 / 1326$ & $0 / 1326$ & $0 / 0$ & $\gamma_{\mathrm{w}} \mathrm{CH}_{2} \mathrm{c}$ Амид III $\left(v_{\mathrm{s}} \mathrm{OCN} \mathrm{c} \sigma \mathrm{NH}\right)$ \\
\hline $0 / 1194$ & $0 / 1286$ & $0 / 8$ & Амид III $+\gamma_{\mathrm{w}} \mathrm{CH}_{2} ; \mathrm{R} \mathrm{SO}_{4}-\cdots \mathrm{H}_{2} \mathrm{O}$ \\
\hline $1080 / 1095$ & $0 / 0$ & $-15 / 0$ & $\begin{array}{c}\gamma_{\mathrm{t}} \mathrm{C}_{2} \mathrm{~N}(\mathrm{NH} \cdots \mathrm{OC}) ; \text { Амид IV; бидентатный } \\
\text { комплекс } \mathrm{Zn}^{2+} \text { c SO-группами }\end{array}$ \\
\hline $983 / 970$ & $983 / 970$ & $0 / 0$ & $\begin{array}{c}\text { монодентатный и бидентатный лиганды } \mathrm{Zn}^{2+} \\
\text { c SO -группами }\end{array}$ \\
\hline $0 / 849$ & $0 / 840$ & $0 / 9$ & С-О- вициальн. с $\mathrm{CH}_{2}$ \\
\hline $741 / 764$ & $741 / 764$ & $0 / 0$ & vАмид $\mathrm{V} ; \gamma_{\mathrm{r}} \mathrm{CH}_{2}$ \\
\hline $612 / 601$ & 604 / 591 & $8 / 10$ & $\begin{array}{c}v \text { Амид } \mathrm{VI}\left(\sigma_{0} \mathrm{C}=\mathrm{O}\right) \text { или } \\
\left.\left[\mathrm{Zn}\left(\mathrm{H}_{2} \mathrm{O}\right)_{4}\right] \mathrm{SO}_{4}^{-} \text {ион (координац. }\right)\end{array}$ \\
\hline $497 / 495$ & $495 / 493$ & $2 / 2$ & v Амид VI бССС скелетн. \\
\hline
\end{tabular}

Наиболее прочные 4-х и 5-ти членные циклы ион $\mathrm{Zn}^{2+}$ образуют с $\mathrm{SO}_{4}^{2-}$ группировками (схема 9):

$$
(\mathrm{C}-\mathrm{C} \% \mathrm{O})^{-} \cdots \mathrm{HN}
$$


<smiles></smiles><smiles>[R]C(=O)N[Z6]([14CH3])(N[14CH3])OC([R])O</smiles>

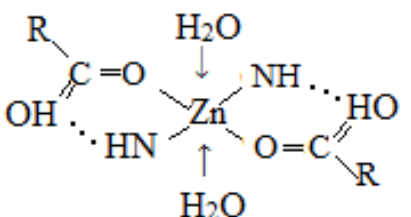

Ионы $\mathrm{Zn}^{2+}$ в реакциях хелатообразования фактически занимают место на уровне $\mathrm{Co}^{2+}$. Ионы $\mathrm{Zn}^{2+}$ с [хитозан + карбоксилат-ионами], NH-метилен-бисакриламидом, [акриламидом + метакриловой кислотой], метиламиноуксусной кислотой могут образовывать 4-х, 5-ти, 6-ти членные комплексы различной устойчивости (в зависимости от природы функциональной группы). Ионы $\mathrm{Zn}^{2+}$ с сульфогруппами, карбоксильными, аминогруппами в качестве лиганда (как правило с 4-х членными циклами) содержат и другие донорные группы (воду, спиртовые группы). Здесь уместно говорить об образовании в суперабсорбенте новых координационных центров $[4,7,17,19]$, в состав которых включены молекулы воды.

Таким образом, установлена возможность существования в модифицированном ионами $\mathrm{Zn}^{2+}$ и $\mathrm{SO}_{4}{ }^{2-}$ координационных соединений $\left[\mathrm{Zn}\left(\mathrm{H}_{2} \mathrm{O}\right)_{4}\right] \mathrm{SO}_{4}$, где ион $\mathrm{SO}_{4}{ }^{2-}$ слабо ассоциирован [19]. Наряду с этим программа УПОС позволила идентифицировать в ИК-спектрах полосы поглощения амидных группировок Амид I - Амид IV, которые взаимодействуют с молекулами воды и способствуют появлению в суперабсорбенте новых координационных аквацентров.

Процессы модификации образцов «твердая вода» сульфатом марганца в определенной мере отличаются от таковых с участием $\mathrm{ZnSO}_{4}$. Связано это с тем, что по Пирсону катион $\mathrm{Mn}^{2+}$ входит в группу 26 и является «легкой кислотой». Для иона $\mathrm{Mn}^{2+}$ характерно по отношению к лигандам повышенное сродство к азоту и сере. Устойчивость комплексов $\mathrm{Mn}^{2+}$ в целом возрастает с уменьшением электроотрицательности донорных атомов [19] (схема 10):

$$
\mathrm{S}-\text { хелат }>\mathrm{S}^{-2}>\mathrm{N}-\text { хелат }>\mathrm{I}^{-}>\mathrm{Br}^{-}>\mathrm{Cl}^{-} \approx \mathrm{NH}_{3}>\mathrm{OH}^{-}>\mathrm{H}_{2} \mathrm{O}>\mathrm{F}
$$

В случае с ионами $\mathrm{Zn}^{2+}$ комплексообразующие анионы располагаются в следующей имперический ряд, характерный по возрастанию устойчивости соответствующих комплексов с А - катионами (схема 11[19]):

$\mathrm{F}^{-}>\mathrm{O}$-хелат $>\mathrm{OH}^{-}>\mathrm{H}_{2} \mathrm{O}>>\mathrm{N}-$ хелат $>\mathrm{Cl}^{-}>\mathrm{Br}^{-}>\mathrm{I}^{-}>\mathrm{NH}_{3}>\mathrm{S}>$ хелат $>\mathrm{S}^{2}(11)$

В связи с этим влагопоглощение суперабсорбентом с $\mathrm{ZnSO}_{4}$ составляет 490 дм $^{3}$ одним килограммом полимера, в то время как с $\mathrm{MnSO}_{4}$ всего 390 дм³/кг.

Таблица 7. Отнесение полос поглощения в ИК-спектрах исходного (числитель) и набухшего (знаменатель) суперабсорбента «Твердая вода» в растворе сульфата марганца.

\begin{tabular}{|c|c|c|c|}
\hline \multicolumn{2}{|c|}{$v, \mathrm{~cm}^{-1}$} & \multirow[b]{2}{*}{$\Delta v, \mathrm{~cm}^{-1}$} & \multirow[b]{2}{*}{ Колебания } \\
\hline Эксперимент & $\begin{array}{c}\text { По программе } \\
\text { УПОС }\end{array}$ & & \\
\hline 1 & 2 & 3 & 4 \\
\hline $0 / 0$ & $359 / 3600$ & -6 & $v \mathrm{H}_{2} \mathrm{O} \cdots \mathrm{H}_{2} \mathrm{O}$ с 2 Н-связями (или $\mathrm{NH}^{\cdots} \cdots \mathrm{OH}_{2}$ ) \\
\hline $0 / 0$ & $3524 / 3492$ & -32 & $v \mathrm{H}_{2} \mathrm{O} \cdots \mathrm{H}_{2} \mathrm{O}$ с 3 Н-связями (или $\mathrm{NH}^{\cdots} \mathrm{OH}_{2}$ ) \\
\hline $3424 / 3388$ & $3424 / 3388$ & -36 & $\begin{array}{c}v \mathrm{H}_{2} \mathrm{O} \cdots \mathrm{H}_{2} \mathrm{O} \text { вблизи с } 4 \text { Н-связями (или } \\
\mathrm{NH}_{2} \rightarrow \mathrm{Mn}^{2+} \text { ) }\end{array}$ \\
\hline $3352 / 3342$ & $3352 / 3345$ & -7 & $\begin{array}{c}v \mathrm{H}_{2} \mathrm{O} \cdots \mathrm{SO}_{4}{ }^{2-} \text { вблизи с } \mathrm{NH} \text { (или } v_{\mathrm{s}} \mathrm{COO}^{-}- \\
\left.\mathrm{H}_{2} \mathrm{O} \text { с } \mathrm{Mn}^{2+}\right)\end{array}$ \\
\hline $0 / 0$ & $0 / 3312$ & - & $v_{\mathrm{S}} \mathrm{OH}_{2} \cdots\left[\mathrm{SO}_{4}^{2-}\right] \cdots \mathrm{H}_{2} \mathrm{O}$ \\
\hline $3267 / 3269$ & $3267 / 3269$ & +2 & $\begin{array}{c}v_{\mathrm{s}} \text { бидентатного лиганда } \mathrm{Mn}^{2+} \mathrm{c} \mathrm{SO} \text { и } \mathrm{H}_{2} \mathrm{O}- \\
\text { группами }\end{array}$ \\
\hline $0 / 0$ & $3154 / 3174$ & +20 & Резонанс Ферми (Амид IIx2 c NH) \\
\hline
\end{tabular}




\begin{tabular}{|c|c|c|c|}
\hline 1 & 2 & 3 & 4 \\
\hline $0 / 2948$ & $2969 / 0$ & & $v_{\mathrm{as}} \mathrm{CH}_{2}$ \\
\hline $0 / 0$ & $2857 / 2856$ & -1 & $v_{\mathrm{S}} \mathrm{CH}_{2}$ \\
\hline $0 / 2660$ & $2639 / 2660$ & +21 & $\sigma \mathrm{COOH}^{\cdots} \mathrm{OH}_{2}$ \\
\hline $0 / 0$ & $0 / 2556$ & - & $\begin{array}{c}\sigma_{\mathrm{as}} \mathrm{OH} \text { в СООН; комплекс } \mathrm{Mn}^{2+} \text { с концевыми } \\
\text { группами аминокислот }\end{array}$ \\
\hline $0 / 0$ & $0 / 2430$ & - & $\sigma_{\mathrm{s}} \mathrm{OH} \cdots-\mathrm{OOC}$ \\
\hline $\begin{array}{l}2360 \\
2320\end{array}$ & $\begin{array}{l}2360 \\
2320\end{array}$ & -40 & $v_{\mathrm{s}} \mathrm{H}$-связи в димерах СООН-групп \\
\hline $1635 / 1657$ & $1635 / 1657$ & +22 & $v_{\mathrm{s}}$ Амид I (или $\mathrm{C}=\mathrm{O} \cdots \mathrm{H}_{2} \mathrm{O} \mathrm{c} \mathrm{Mn}{ }^{2+}$ ) \\
\hline $0 / 1540$ & $1570 / 1540$ & -30 & $v_{\mathrm{s}}$ Амид II C-N и $\sigma_{\mathrm{s}} \mathrm{N} ;$ и $v$ NH $\cdots \mathrm{O} \mathrm{H}$ \\
\hline $1434 / 1448$ & $1434 / 1448$ & +14 & $\begin{array}{c}\sigma_{\text {II }} \text { вициальный } \mathrm{CH}_{2} \text {; вициальные амидные } \\
\text { связи }\end{array}$ \\
\hline $0 / 1409$ & $0 / 1409$ & - & $\sigma_{\text {II }}$ вициальный $\mathrm{CH}_{2} ;>\mathrm{C}=\mathrm{O}$ \\
\hline $\begin{array}{l}0 / 1323 \\
0 / 1278\end{array}$ & $\begin{array}{l}-/ 1323 \\
0 / 12780\end{array}$ & - & $\begin{array}{l}\gamma_{\mathrm{w}} \mathrm{CH}_{2} \text { с Амид III }\left(v_{\mathrm{s}} \mathrm{OCN} \text { c } \sigma \mathrm{NH}\right) \\
\text { Амид III }+\gamma_{\mathrm{w}} \mathrm{CH}_{2}: \mathrm{RSO}_{4}^{-\cdots} \cdots \mathrm{H}_{2} \mathrm{O}\end{array}$ \\
\hline $1081 / 1098$ & $1081 / 1098$ & +17 & $\gamma_{\mathrm{t}} \mathrm{CH}_{2} ; \sigma \mathrm{CONH}$ (Амид IV) \\
\hline $1002 / 0$ & $1002 / 0$ & & $\sigma$ CONH Амид IV \\
\hline $0 / 258$ & $0 / 850$ & - & вициальные Н-связи С-О с СН или $_{2} \mathrm{r}$ \\
\hline $741 / 766$ & $741 / 766$ & $0 / 0$ & vАмид $\mathrm{V} ; \gamma_{\mathrm{r}} \mathrm{CH}_{2}$ \\
\hline $596 / 590$ & $596 / 590$ & $0 / 0$ & $\begin{array}{c}\text { v Амид VI }\left(\sigma_{0} \mathrm{C}=\mathrm{O}\right) \text { или } \\
{\left[\mathrm{Mn}\left(\mathrm{H}_{2} \mathrm{O}\right)_{4}\right] \mathrm{SO}_{4}^{-} \text {координац. }}\end{array}$ \\
\hline $0 / 540$ & $0 / 0$ & - & бССС скелетн. \\
\hline
\end{tabular}

В ИК-спектрах сорбента, модифицированного сернокислым марганцем, вопервых, имеется меньшее количество характеристических максимумов по сравнению с сорбентом, обработанным сернокислым цинком, и во вторых, положение этих максимумов свидетельствует о меньшей энергии связи иона $\mathrm{Mn}^{2+}$ с $\mathrm{C}=\mathrm{O}$ лигандами (рис. 7, 8; табл. 7).

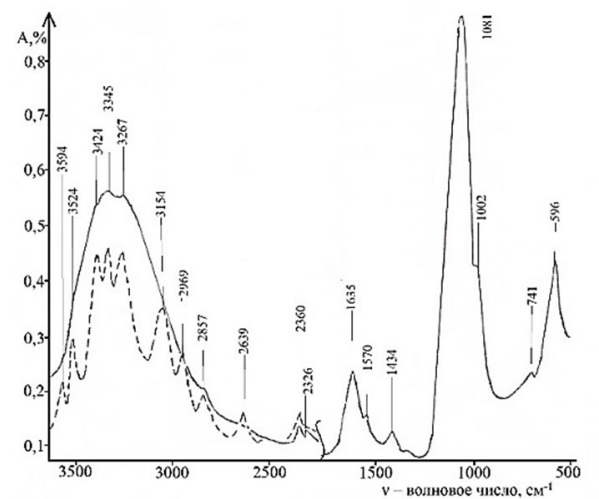

Рис. 7. ИК-спектры исходного (сухого) суперабсорбента «Твердая вода» с ионами сульфата марганца в растворе

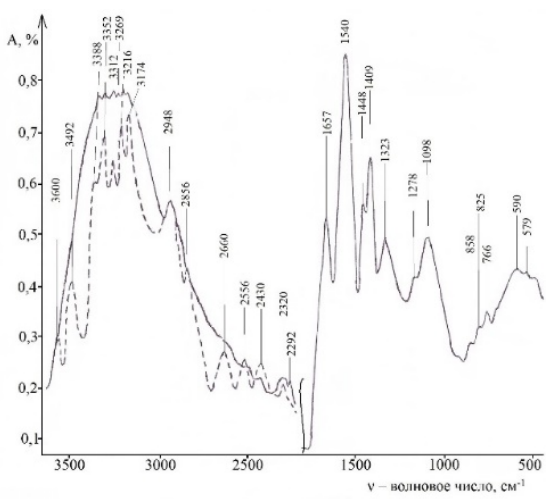

Рис. 8. ИК-спектры сорбента «Твердая вода» в растворе сульфата марганца.

Гидратные комплексы модифицированного сульфатом марганца сорбента содержат большее количество слабосвязанной воды по сравнению с цинксодержащим сорбентом, о чем свидетельствует наличие полос поглощения в области 3600$3270 \mathrm{~cm}^{-1}$ (табл. 7). Кроме того, в сорбенте с $\mathrm{Mn}^{2+}$-ионами ослаблены полосы колеба-

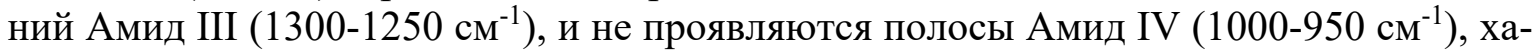
рактерные бидентатным и монодентатным лигандам с сульфат-ионами. Таким обра- 
зом, структура координационных центров в цинкосодержащих и марганецсодержащих суперабсорбентах отличаются друг от друга.

\section{Заключение}

В ходе исследования рассмотрено влияние электролитов $\mathrm{ZnSO}_{4}$ и $\mathrm{MnSO}_{4}$ в качестве микроэлементов на поглощение воды суперабсорбентом, а также предложен способ определения установления энергетических параметров водородных связей в системе суперабсорбент - вода. Показано, что наибольшая энергия водородных связей характерна для гидроксокомплексов с участием карбоксилатных или карбоксильных групп в матрице сорбента. Для увеличения количества воды, поглощаемой суперабсорбентом, необходимо использовать его в катионной или анионной форме.

Данные ИК-спектров свидетельствует о том, что гидратные комплексы модифицированного сульфатом марганца сорбента содержат большее количество слабосвязанной воды по сравнению с цинксодержащим сорбентом. Таким образом, структура координационных центров в цинкосодержащих и марганецсодержащих суперабсорбентах отличаются друг от друга. Влагопоглощение суперабсорбентом с $\mathrm{ZnSO}_{4}$ составляет 490 дм $^{3}$ одним килограммом полимера, в то время как с $\mathrm{MnSO}_{4}$ всего 390 дм³ $^{3}$ кг.

\section{Результаты ИК-спектроскопического исследования получены на оборудовании Центра коллективного пользования научным оборудованием Воронежского государственного университета.}

\section{Список литературы}

1. Кузнецов В.А., Селеменев В.Ф., Семенов В.Н., Бакалова М.В.. Патент РФ № 2574722. Опубл. 10.02.2016 БИ №4.

2. Семенов В.Н., Зенищева А.В., Селеменев В.Ф., Кузнецов В.А. и др. // Сорбционные и хроматографические проиессы. 2018. № 5. C. 690-695.

3. Зенищева А.В., Семенов В.Н., Кузнецов В.А., Кущев П.О. // Конденсированные среды и межфазные гранииьы. 2020. № 1. С. 66-74.

4. Дехант И., Данц Р., Киммер В., Шмольке Р. Инфракрасная спектроскопия полимеров. М. Химия. 1976. 472 с.

5. Карякин А.В., Кривенцова Г.А. Состояние воды в органических и неорганических соединениях. М. Наука. 1973. 174 с.

6. Иогансен А.В. Водородная связь. М. Наука. 1981. С. 112-155.

7. Пиментел Дж., Мак-Клеллан О. Водородная связь. М. Мир. 1964. 462 с.

8. Углянская В.А. Чикин Г.А., Селеменев В.Ф., Завьялова Т.А. Инфракрасная спектроскопия ионообменных материалов. Воронеж. ВГУ. 1989. 207 с.
9. Казицына Л.А., Куплетская Н.Б. Применение УФ-, ИК- и ЯМР-спектроскопии в органической химии. М. Высшая школа. 1971. $264 \mathrm{c}$.

10. Bull H.B., Breese K. Protein hydration. Archives of Biochemistry and Biophysics. 1968. pp. 488-496.

11. Селеменев В.Ф. Рудаков О.Б., Славинская Г.В., Дроздова Н.В. Пигменты пищевых производств. Меланоидины. М. ДеЛи принт. 2008. $246 \mathrm{c}$.

12. Selemenev V.F., Chikin G.A., Khokhlov V.Yu. Jn: Ion-exchange. New York. Marsel Dekker. 2000 (1). pp. 851-925.

13. Кучеров А.П., Кочубей С.М. // Журн. Прикладн. Спектроскопии. 1983. Т. 38. №1. С. 146-150.

14. Кучеров А.П. // Журн. Прикладной спектроскопии. 1984. Т. 41. № 1. С.79-82.

15. Кучеров А.П., Кравец Б.К., Сердюк Л.А., и др. // ГосФАП, №50850000513 от 17.06.1985.

16. Цундель Г. Гидратация и межмолекулярное взаимодействие. М. Мир. 1972. 404 с.

17. Селеменев В.Ф. Хохлов В.Ю., Бобре- 
шова О.В., Аристов И.В., Котова Д.Л. Физико-химические основы сорбционных и мембранных методов выделения и разделения аминокислот. Воронеж. ВГУ. 300с.

18. Накамото К. ИК-спектры и спектры КР неорганических и координационных соединений. М. Мир. 1991. 536 с.

19. Умланд Ф., Янсен А., Тириг Д., Вюнш Г. Комплексные соединения в аналитической химии. М. Мир. 1975.531 с.

\title{
Interaction of the superabsorbent "Solid water" modified by zinc and manganese ions with water
}

\author{
(C)2020 Zenishcheva A.V., Semenov V.N., Kuznetsov V.A., \\ Kuschev P.O., Lukin A.N.
}

Voronezh State University, Voronezh

\begin{abstract}
One of the problems being discussed in the agricultural sector is climate change and global warming, which lead to the expansion of arid areas and changes in soils. These lead to increased agricultural risks in these areas. Traditional methods of irrigation and application of mineral fertilizers and trace elements are not always available and effective. For the economic benefit and intensification, a previously synthesized rarecross-linked polymer material with the properties of the "Solid water" superabsorbent can be used as a reservoir to maintain the required humidity level and to introduce the necessary trace elements into the soil.

This paper studies the hydration properties of samples of the "Solid water" superabsorbent modified with zinc sulphate and manganese sulphate (II) salts. The purpose of the research was to clarify and correct earlier results of the hydration of samples of the "Solid water" sorbent, as well as to establish the effect of electrolytes $\mathrm{ZnSO}_{4}$ and $\mathrm{MnSO}_{4}$ as trace elements on the absorption of water by the superabsorbent. The experiment determined the ability of modified sorbent samples to absorb moisture. Also, a method to determine the establishment of energy parameters of hydrogen bonds in the superabsorbent - water system was proposed. A universal spectrum processing program (UPOS) based on IR spectroscopy data was used for this purpose. A possible variant of the formation of water - metal ion hydroxocomplexes in the phase of a sorbent modified with trace elements was proposed.

The study showed that the highest energy of hydrogen bonds is characteristic of hydroxocomplexes with the participation of carboxylate or carboxyl groups in the sorbent matrix. To increase the amount of water absorbed by the superabsorbent, it is necessary to use it in a cationic or an anionic form. For the first time, the formation of monodentate and bidentate ligands was established during the interaction of the superabsorbent with zinc sulfate ions in a solution. It was found that more stable associates are formed by $\mathrm{Zn}^{2+}$ ions with $\mathrm{COOH}$-and amino groups, compared to $\mathrm{Mn}^{2+}$ ions. IR spectroscopy data confirm that the moisture absorption of a superabsorbent with $\mathrm{ZnSO}_{4}$ is $490 \mathrm{dm}^{3}$ per kilogram of polymer, while with $\mathrm{MnSO}_{4}$ it is only $390 \mathrm{dm}^{3} / \mathrm{kg}$.

Keywords: superabsorbent, hydration properties, moisture absorption, zinc sulphate, manganese sulphate, IR spectra
\end{abstract}

\section{References}

1. Kuznetsov V.A., Selemenev V.F., Semenov V.N., Bakalova M.V., Russian patent No 2574722. Publ. 10.02.2016 BI №4.

2. Semenov V.N., Zenishcheva A.V., Selemenev V.F., Kuznetsov V.A. et al, Sorbtsionnye $i$ khromatograficheskie protsessy, 2018, No 5, pp. 690-695.

3. Zenishcheva A.V., Semenov V.N., Kuznetsov V.A., Kushchev P.O., Condensed media and interfacial boundaries, 2020, No 1, pp. 6674.

4. Dekhant I., Dants R., Kimmer V., Shmol'ke R. Infrared spectroscopy of polymers, M., Chemistry, 1976, $472 \mathrm{p}$.
5. Karyakin A.V., Kriventsova G.A. State of water in organic and inorganic compounds, M., Nauka, 1973, 174 p.

6. Iogansen A.V. Hydrogen bonding, M., Nauka, 1981, pp. 112-155.

7. Pimentel Dzh., Mak-Klellan O. Hydrogen bond, M., Mir, 1964,462 p.

8. Uglyanskaya V.A. Chikin G.A., Selemenev V.F., Zav'yalova T.A. Infrared spectroscopy of ion-exchange materials. Voronezh, VSU, 1989, $207 \mathrm{p}$.

9. Kazitsyna L.A., Kupletskaya N.B. Application of UV, IR and NMR spectroscopy in organic chemistry, M., Higher school, 1971, 264 p. 
10. Bull H.B., Breese K. Protein hydration. Archives of Biochemistry and Biophysics, 1968, pp. 488-496.

11. Selemenev V.F. Rudakov O.B., Slavinskaya G.V., Drozdova N.V., Pigments for food production. Melanoidins, M., Delhi print, 2008, $246 \mathrm{p}$.

12. Selemenev V.F., Chikin G.A., Khokhlov V.Yu. Ion-exchange, New York, Marsel Dekker, 2000 pp. 851-925.

13. Kucherov A.P., Kochubei S.M., Journal. Applied. Spectroscopy, 1983, Vol. 38, No 1, pp. 146-150.

14. Kucherov A.P. Zhurn. Applied spectroscopy, 1984, Vol. 41, No 1, pp 79-82.

15. Universal spectrum processing program

Зенищева Анна Витальевна - аспирант кафедры общей и неорганической химии, Воронежский государственный университет, Воронеж

Семенов Виктор Николаевич - д.х.н., профессор, заведующий кафедрой общей и неорганической химии, Воронежский государственный университет, Воронеж

Кузнецов Вячеслав Алексеевич - д. х. н., профессор, кафедра высокомолекулярных соединений и коллоидной химии, Воронежский государственный университет, Воронеж, еmail:dr.v.kuznetsov@gmail.com

Кущев Петр Олегович - к. х. н., преподаватель кафедры высокомолекулярных соединений и коллоидной химии, Воронежский государственный университет, Воронеж

Лукин Анатолий Николаевич - к. ф. -м. н., доцент кафедры физики твердого тела и наноструктур, Воронежский государственный университет, Воронеж
(UPOS) / Kucherov A.P., Kravets B.K., Serdyuk L.A., i dr. // GosFAP, №50850000513 ot 17.06.1985.

16. Tsundel' G., Hydration and intermolecular interaction, M., Mir, 1972, $404 \mathrm{p}$.

17. Selemenev V.F. Khokhlov V.Yu., Bobreshova O.V., Aristov I.V., Kotova D.L., Physico-chemical bases of sorption and membrane methods of separation and separation of amino acids, Voronezh, VSU, 300 p.

18. Nakamoto K. IR spectra and RAMAN spectra of inorganic and coordination compounds, M., Mir, 1991, 536 p.

19. Umland F., Yansen A., Tirig D., Vyunsh G., Complex compounds in analytical chemistry, M., Mir, 1975, 531 p.

Zenishcheva Anna V. - graduate student of the Department of General and Inorganic Chemistry, Voronezh State University, Voronezh, Russian Federation; e-mail: anvitz@mail.ru

Semenov Victor N. - DSc in Chemistry, Full Professor, Head of the Department of General and Inorganic Chemistry, Voronezh State University, Voronezh, e-mail: semenov@chem.vsu.ru.

Kuznetsov Vyacheslav A. -DSc in Chemistry, Professor, Department of High-Molecular Compounds and Colloid Chemistry, Voronezh State University, Voronezh, e-mail: dr.v.kuznetsov@gmail.com

Kuschev Petr O. - PhD in Chemistry, Lecturer at the Department of High-Molecular Compounds and Colloid Chemistry, Voronezh State University, Voronezh, e-mail: peter.kuschev@gmail.com.

Lukin Anatoly N. -PhD of Physico-mathematical Sciences, associate Professor, Department of solid state physics and nanostructures, Voronezh State University, Voronezh, e-mail: ckp_49@mail.ru. 